https://doi.org/10.48009/1_iis_2010_696-710

\title{
VALIDATING A COMPREHENSIVE MODEL FOR ONLINE SOCIAL NETWORKING USE:INITIAL RESULTS
}

Thilini Ariyachandra, ariyachandrat@xavier.edu

Nancy Bertaux, Xavier University, bertaux@ @ xavier.edu

\begin{abstract}
While there are a number of studies that investigate the impetus for and impact of online social networking, there are fewer studies that attempt to formulate and test a truly comprehensive model of what influences people to use social networking sites. This study builds on a previous study of Midwestern U.S. college-aged individuals, through significant expansion of the number of variables investigated, as well as a reconceptualization of their interrelationships. This paper describes the conceptual model and gives results from a new survey, repeated from the same general population. These results suggest that individuals' desire to get information, and their enjoyment of social networking sites significantly influence both their decision to use such sites, and the intensity with which the sites are utilized. Web experience and social norms are also identified as significant influences on usage. Privacy and trust concerns appear to be eclipsed by the enjoyment and desire to get information from social networking. This research should add to our understanding of who uses social networking and why, as well as identify areas for further research.
\end{abstract}

\section{INTRODUCTION}

Information technology (IT) is playing an increasingly important role in people's lives of people, as the Internet and telecommunications bring changes to daily life, learning, and work (Venkatesh et al, 2003; Walsham, 2008). The exponential growth in Internet access has created a similar growth in the number of users. In 2000, global Internet use was at 0.4 billion; the latest usage statistics from December 2009 indicates a increase in use to 1.8 billion users. The growth in Internet usage in the past 9 years has thus been around 400 percent. The new and improved
Web, Web 2.0, has created a sophisticated user base with new online functionality and tools such as blogs, wiki's, online social networking, with all incorporating higher interactivity and collaboration (Miniwatts Marketing Group, 2010). Niche groups operating in online social networks provide individuals with similar professions or interest to pursue causes and share information that benefits group members. From a business standpoint, knowing who uses social networking sites and their motivations may facilitate marketing of products and services. Increasingly, the growth and enhancements to the Web has made it an essential tool for business, education, government, and entertainment (Warr, 2008).

Online social networking is currently in the midst of an explosion of popularity, as well as an explosion of questions about the costs, benefits, and future of this technology. For many users of the Internet, checking social networking sites has become part of daily computer usage, and numbers of these intensive users is rising rapidly ("A World of Connections," 2010; Smith, 2008). As a result of Web 2.0, the Internet is changing from merely a place to get information, or even a place to give information, to a place to access a whole set of interactive applications and online sharing and collaboration (Anderson, 2007). Predictably, social networks are increasingly looking for ways to profit from the sites' popularity ("Profiting from Friendship," 2010). Issues surrounding the social networking aspect of the information revolution range from the significance of such networking for human relationships (Pelling and White, 2009; Panzarasa et al, 2009) to persistent securityrelated concerns, both for younger people and for people of all ages ("Privacy 2.0," 2010; Tagvoryan and Briones, 2009), to questions regarding workplace productivity ("Yammering Away at the Office," 2010; McAfee, 2009; Neumann et al, 2005).

While there are a number of studies that investigate the impetus for and impact of online 
social networking, there are fewer studies that attempt to formulate and test a truly comprehensive model of what influences people to use social networking sites. This study seeks to address the objective of formulating and testing a truly comprehensive model of influences on social networking usage by building on a previous study of Midwestern U.S. college-aged individuals. Based on the results of the previous study, a new conceptual model is described, with significant expansion of the number of variables investigated, as well as a reconceptualization of their interrelationships, and the model is tested with data from a new survey, repeated from the same general population as the previous survey. The rest of this paper is presented in the following manner. First, the paper identifies the conceptual model used, and a description of how the model was developed. Next, the factors identified as potential influences on social networking usage are discussed, in the context of the existing literature. Then, the methodology used is described, and the results of the data analysis are presented. The paper concludes with final thoughts, including implications for future research.

\section{Comprehensive Conceptual Model of Influences on Online Social Networking Usage}

The analysis of the earlier study referred to above (Ariyachandra and Bertaux, 2009) indicated that some variables that were predicted to be significant influences did not emerge as statistically significant in the study. The analysis suggested that an expansion of the number of variables investigated, and a reconceptualization of their interrelationships, might be helpful in developing a better understanding of the factors influencing online social networking behavior.

Following analysis that included reviewing the earlier study's quantitative and open-ended, qualitative survey responses, as well as updating knowledge of other literature in the area, the following conceptual model was developed (see Figure 1 below): 


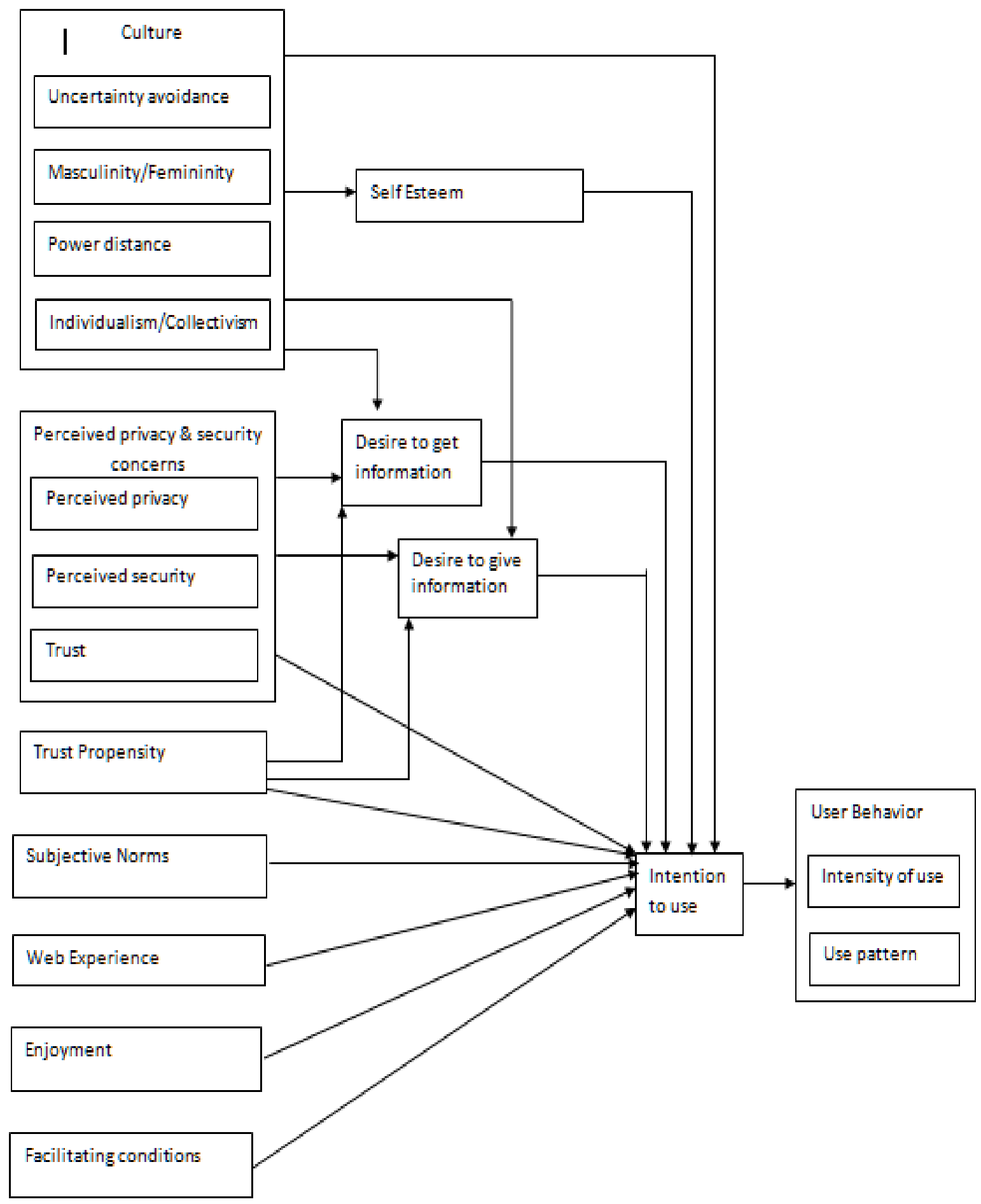

\section{Figure 1: Comprehensive Model for Social Networking Use}

In this model, cultural variables, and perceived privacy, security and trust variables influence the intention to use online social networking, both indirectly through the desire to get and give information, and directly. A number of other variables, including subjective social norms, web experience, enjoyment, and facilitating conditions can directly influence intention to use. 
In turn, intention to use is conceptualized as influencing user behavior, both in terms of intensity and pattern of use. The decision to focus on intention to use and then user behavior (intensity and pattern of use) as the variables to be explained (or dependent variables) was based on numerous studies in the literature on information systems in general, as well as social networking sites in particular, which have effectively used these variables (Venkatesh et al, 2003; Yi and Hwang, 2003; Taylor and Todd 1995). Below is a discussion of the literature on the variety of explanatory variables considered.

\section{Factors that Influence Social Networking}

While both offline and online social networking behavior have been extensively studied, online social networking, as a relatively recent phenomenon, is much less understood. In addition, rapid changes occurring in online social networking have made studying this area difficult, since by the time one modality or site begins to be thoroughly studied, users have moved on to new modalities and sites. Some of the popular press concerning social networking sites has been negative in focus (Cain 2008), yet the popularity of online social networking continues to grow at a remarkable pace. Still, social networking sites involve numerous issues, and even controversy.

\section{Privacy, Security and Trust}

Some of the issues that have received the most attention with respect to online social networking concern privacy, security, and trust, and related propensities and attitudes toward revealing personal information to the world. Studies of privacy, trust and security issues in e-commerce have revealed that these issues are crucial in winning the levels of public trust that are essential for the growth of e-commerce. One early study found that consumer ratings of trustworthiness did not match those of experts, that security features were valued more highly than privacy statements or seals, and that convenience and ease of use took precedence over privacy and security in buyers' decisions (Belanger et. al., 2002).

One of the first studies to research privacy and trust as applied to social use of the internet is an ethnographic study of the first popular social networking site, Friendster (Boyd 2004). The study documents the influence of privacy issues on member participation and the maintenance of friendship connections, and describes how members create their profile with the intention of communicating news about themselves to others. Another early study of trust in virtual communities concluded that trust affected intentions to both give and get information, and that trust was raised when individuals had a higher trust disposition, and when they experienced positive relationships in the community. Subsequent studies, although motivated by e-commerce applications, focused carefully on how trust can be reliably measured, proposing and testing a number of specific constructs and subconstructs related to trust in the context of Internet usage (McKnight et. al., 2005; Chen and Barnes, 2007). Several studies examining the two most popular social networking sites today, Facebook and MySpace, also analyze profile information and member surveys to understand privacy and information sharing practices (Acquisti and Gross, 2006; Ellison, Lampe, and Steinfield, 2007; Stutzman, 2006).

A study conducted by Acquisti and Gross (2006) focusing on social networking membership, information sharing, and privacy issues of college students revealed that members' privacy concerns did not necessarily coincide with their usage and behaviors on social networks. However, no information on the empirical validation of the survey instrument used was provided. The same researchers conducted another study into privacy issues by analyzing Facebook profiles (Gross and Acquisti 2006). The findings indicated that $99 \%$ of user did not change the default privacy settings to limit information sharing and many provided large amounts of personal information online.

A subsequent study examined how privacy and trust influence social interactions by comparing the two popular social networking sites, Facebook and MySpace (Dwyer 2007). The study revealed that online relationships can develop in sites where perceived trust and privacy safeguards are weak. However, the researchers conclude that the interaction of trust and privacy concern in social networking sites is not yet sufficiently understood to provide an accurate understanding of usage and they encourage further research on this issue. Given the popular media hype on privacy invasion and social networking as well as on news releases describing criminal liability as well as college suspensions resulting from usage and behavior 
on social networks (Gianino 2007), privacy and trust may have a distinct influence on social networking usage.

Several more recent studies of privacy and security issues have focused on the rise of legal concerns about websites such as Facebook, asking questions about who is required to protect privacy and how, especially when users have made information publicly available, and discussed Facebook's policies on privacy settings as a way of addressing such concerns (Tagvoryan and Briones, 2009; Flint, 2009). Another recent study of adolescent disclosure of personal information on web sites used survey data from middle school students to show that students had higher levels of privacy concern when they perceived higher levels of risk, but lower levels of privacy concern when they perceived higher levels of benefit from sharing information, and that their levels of privacy concern did affect usage behaviors (Youn, 2009).

Based on the past literature, perceived privacy, security, and trust were all chosen as major factors that influence social networking usage.

\section{Culture, Social Norms and Demographic Factors}

Lesser-studied factors that may influence social networking usage include factors related to cultural background, social norms, and a variety of demographic characteristics, notably including gender.

Prior studies of gender and information technology have found a significant "gender gap" based on barriers facing women and girls, especially in the developing world (Abu-Rashed et al, 2007; Jackson, 2007). While this gap might cause researchers to postulate lesser usage of social networking sites among females, the purposes and format of the sites are also consistent with possibly higher interest levels among females, so that the impact of gender is unclear a priori. A recent study surveyed male and female U.S. college students (from the same population as the survey performed for this article) and found that while gender did affect web experience, trust and perceived privacy levels of social networking sites, and trust did significantly affect social networking usage, gender did not directly, significantly affect usage of these sites. The males and females in the study used social networking sites for similar amounts of time (Ariyachandra and Bertaux, 2009). Based on this result, while we identified gender and other demographic factors as potential influences, we recognized that gender may not be a major influence in the population studied here. However, in our subsequent study across international cultures, we plan to again reintroduce gender, as these results may be different outside the U.S.

Recently, some cross-cultural research on social networking has begun to emerge. One study compared the US-based Facebook and Japanbased Mixi, finding that the design of the sites reflected cultural differences, with Facebook being more assertive and Mixi more subtle (Fogg and Iizawa, 2008). This study highlights the fact that in different nations, specific social networking sites may be extremely popular (for example, Skyrock in France and Cyworld in South Korea), and that there can be big differences among them (Reisinger, 2009; MacMillan, 2009). One recent cross-cultural study of social networking utilized ethnographic methods including observation and interviews to examine aspects of social networking behavior of individuals in four countries (the US, France, China and South Korea). This study found three areas of cultural difference in social networking: users' goals, typical pattern of self-expression, and common interaction behaviors (Chapman and Lahav, 2008).

A 2006 study on acceptance of new technology in general considered the role of national cultural values of masculinity/femininity, individualism/collectivism, power distance, and uncertainty avoidance, and found that social norms were stronger predictors of technology acceptance among those with feminine and high uncertainty avoidance cultural values; however, these values did not affect the linkage between perception of usefulness and intent to use the technology (Srite and Karahanna, 2006). A study of online social networking among university students in India and the US found common communication patterns in their social networking usage, and also found that when they differed, they sometimes contradicted what would be expected from the US/individualist, India/collectivist categorization (Marshall et al, 2008). Another recent study of social networking among university students in eleven countries in North America, Europe, Asia and the Middle East, using data on nationality, gender and age, found that levels of 
individualism vs. collectivism in cultural background did not lead to different numbers of offline friends or online social ties. However, the study did find that frequent social network users in individualist nations had more offline social ties, and this was not the case with frequent social network users in collectivist nations (Cardon et al, 2009). Other research on social networking usage has focused on crosscultural issues such as adaptation of international students to host countries (Ye, 2006).

Based on the past literature, cultural variables, subjective social norms and demographic variables were identified as potential factors influencing social networking usage.

\section{Web Experience, Enjoyment, and Facilitating Conditions}

Researchers have identified users' experience with the web and other computer-related experience, computer-related self-efficacy, enjoyment of use, and facilitating conditions such as ease of use as factors that influence adoption of new technology, and of usage of Web-based information systems in general (Venkatesh et al, 2003; Yi and Hwang, 2003; Eastin and LaRose, 2000; Taylor and Todd 1995). Studies have found similar results regarding the usage of social networking sites (Eastin and LaRose, 2000). For example, a study of young adults that people with higher levels of web experience and autonomy of use were more likely to be users of social networking sites (Hargittai, 2007). Studies have sometimes categorized users of online social networking according to their web experience profiles; one study divided users into three categories: passive users of the network, users who invite offline friends to join, and those who participate in the evolution of the network (Kumar et al, 2006). A recent study of adoption of new technology has described "information cascades" that can cause individuals to adopt the technology when they become aware of the adoption decisions of others, and further, has analyzed how this process can occur through information given on social networking sites (Chesney et al, 2010). Thus, we can see that social networking sites can themselves be facilitating conditions for the adoption of new technology.

Enjoyment as an influential variable in usage is particularly important in the case of social networking sites (Yi and Hwang, 2003). These sites are comparable to online gaming in the fact that the motivation for use is highly associated with recreation and socializing, although this may be especially true for young people (Boyd, 2007). There is some evidence that older users may be more focused on using online social networking for professional and business purposes, which may imply less emphasis on enjoyment ("Profiting from Friendship," 2010).

Based on past literature, web experience, enjoyment, and facilitating conditions variables were included as major factors that influence social networking usage.

\section{Desire to Get and Give Information}

Based on the authors' own analysis of prior studies, two new variables were included that have not been previously utilized in quantitative studies as factors directly influencing social networking usage: the desire to get information and the desire to give information. While these are new variables in this specific type of study, there is a basis in psychology, organizational learning, and other literature for these variables, and some conceptual models have included these variables (Mikami et al, 2010; Huber, 1991; Davenport and Klahr, 1998).

The desire to get information is a key motivational factor discussed in the literature on learning and information/knowledge management (Grover and Davenport 2001). While the study here focuses on individuals' desires to get information, it is important to note that there is a significant literature on organizations' motivations to acquire information and knowledge (Huber, 1991). With respect specifically to online social networking, scholarly descriptions of social networking sites invariably address users' desire for information about other users, and, more recently, about information on events and activities that can be accessed from these sites (Boyd and Ellison, 2007).

The desire to give information is also a key reason for users to participate in social networking sites. Scholars focused on individuals' using these sites to invent, or reinvent their identities through photo-sharing and other means, and terms such as "impression management" have been used in this regard (Boyd and Ellison, 2007; Boyd 2007). Researchers have also considered the long-term 
viability of social networking sites, noting that profitability will be a major factor, and that joining the sites is a good deal easier and less time-consuming than maintaining a presence and pursuing online relational activity on an ongoing basis (Kent, 2008). It is interesting to note that social networking sites often involve the exchange of information, that is, giving and getting information in return. Scholars have noted that such sites are essentially redefining "word of mouth" communication, and this is of great interest to many social institutions, including those related to business and marketing (Brown et al, 2007).

\section{Research Methodology}

The research study had two phases. In the first phase, the results of a qualitative open-ended question survey conducted on 114 students was combined with literature and theory related to online social networking to create a comprehensive research model. In the study's second phase, a survey instrument was developed and tested, and data was collected from 208 student respondents and analyzed to test the research model $^{1}$.

\section{Instrument development}

According to Straub et al (2004), one of the challenges of positivist quantitative research is accurately capturing and measuring the social phenomena. Although many researchers use existing items when possible, Swanson (1991) suggest that the context of existing research measures and questionnaires may not apply to a researcher's current project as the measures are deeply embedded in the research project that they pertain to. As a result, a researcher must exercise caution when adopting existing measures and should serve only as useful starting point in operationalizing variables of interest (Zmud et al. 1991).

Past literature and theory was utilized whenever possible to develop the questionnaire items.

\footnotetext{
${ }^{1}$ While a comprehensive model was developed and operationalized to capture all the factors that could influence social networking use, as initially the study intent lay in testing and validating the model with population in the United States, some of the factors were omitted from data collection and analysis. For example, each of the cultural dimensions were omitted.
}

However, when appropriate items were unavailable, a deductive, iterative approach to item development was used (Hinkin 1995). Multiple items were generated for each construct and refined through multiple iterations of review from sample respondents and co-researchers. Finally, five graduate student assistants were asked to pretest the online questionnaire. After several minor modifications were made, the resulting questionnaire contained 17 constructs, its items and demographic questions. Most of the questions employed a seven-point Likert scale anchored at strongly disagree (1) and strongly agree (7). Next, in order to understand what influences social network usage and behavior, an online survey was created and administered to students at a university in the Midwest. Some of the questions and their underlying constructs were omitted from the questionnaire as during the pretest with graduate students it became obvious that the survey instrument as is was too long. As such the cultural dimensions as well as trust, facilitating conditions and usage pattern were omitted from the final questionnaire. Since trust propensity would be captured, trust was eliminated. Facilitating conditions was also removed from the questionnaire as the researchers felt that Web experience represented a key facilitating condition to social networking use. In a similar vein, usage pattern was omitted as intention to use and intensity of use would be captured.

The participants were queried on their social network usage patterns, as well as on what influences their usage. Students were given modest incentives in the form of extra credit to complete the survey, and encouraged by their professors to take their time and answer questions as accurately as possible. Thus a favorable response rate was achieved, with 208 total responses.

\section{Results of Data Analysis}

Data gathered from 208 survey participants were analyzed using SPSS 17.0 to conduct a number of different tests. The survey participants were undergraduate students from a variety of majors (participating students received an extra credit point for completing the online survey). Of the 208, 5 were incomplete unusable responses leaving 203 data points for data analysis. Overall, about $32 \%$ of the respondents were female and $68 \%$ male. The respondents spent an average of almost 7 hours per week on social 
networking Websites (with Facebook as the most common site used), and they logged on 3.55 times on average each day to a social network.

An exploratory factor analysis (EFA) was conducted to assess the unidimensionality of items and constructs using principal components analysis with a promax rotation. As response variables were expected to co-vary with their predictors, the variables were divided into two groups to assess measurement models. The two groups were an influence factors group (i.e., SN influence) consisted of variables intended to measure the factors that influence social networking use and a social network use group (SN use) consisted of variables intended to measure social network usage.

\begin{tabular}{|c|c|c|}
\hline Reliability & ITEM & Loading \\
\hline \multirow[t]{3}{*}{$\begin{array}{l}\text { Desire to Get } \\
(0.9345)\end{array}$} & $\begin{array}{l}\text { I generally like to find out as much as possible about people I } \\
\text { know }\end{array}$ & 0.903 \\
\hline & I like to get information on potential new friends when available. & 0.925 \\
\hline & $\begin{array}{l}\text { I enjoy staying updated on my friends, family and } \\
\text { acquaintances. }\end{array}$ & 0.914 \\
\hline \multirow[t]{2}{*}{$\begin{array}{l}\text { Desire to Give } \\
(0.9073)\end{array}$} & $\begin{array}{l}\text { I don't hesitate to react or give my opinion online to my friends, } \\
\text { family and acquaintances. }\end{array}$ & 0.873 \\
\hline & I generally like to be the first to spread the word. & 0.926 \\
\hline \multirow{3}{*}{$\begin{array}{l}\text { Social Norms } \\
(0.7649)\end{array}$} & My relatives think that I should use this Website. & 0.812 \\
\hline & My professors think I should use this Website. & 0.756 \\
\hline & I believe that my classmates think I should use this Website. & 0.628 \\
\hline \multirow{3}{*}{$\begin{array}{l}\text { Enjoyment } \\
(0.8729)\end{array}$} & Using this Website is exciting. & 0.801 \\
\hline & I enjoy online social networking. & 0.883 \\
\hline & Using this Website gives me a lot of pleasure. & 0.839 \\
\hline \multirow[t]{3}{*}{$\begin{array}{l}\text { Self Esteem } \\
(0.9401)\end{array}$} & $\begin{array}{l}\text { I feel that I'm a person of worth, at least on an equal plane with } \\
\text { others. }\end{array}$ & 0.884 \\
\hline & I am able to do things as well as most other people. & 0.965 \\
\hline & On the whole, I am satisfied with myself. & 0.913 \\
\hline
\end{tabular}

The initial EFA factor matrix for each group indicated that all items loaded well above 0.60 (Comrey et al. 1992). Cronbach alpha values were used to assess the reliability of the items associated with the latent constructs. According to Gefen et al (2000), Cronbach alphas for constructs in exploratory studies should exceed 0.60 , and in confirmatory studies they should exceed 0.70 . The internal consistency of constructs in this study surpassed the suggested guidelines for exploratory studies. The factor loadings as well as the reliability measures for each construct are presented in Table 1. 


\begin{tabular}{|c|c|c|}
\hline \multirow{2}{*}{$\begin{array}{l}\text { Security } \\
(0.9267)\end{array}$} & This web site presents enough online security. & 0.917 \\
\hline & This web site has the ability to solve problems from hackers. & 0.892 \\
\hline \multirow[t]{4}{*}{$\begin{array}{l}\text { Privacy } \\
(0.8876)\end{array}$} & $\begin{array}{l}\text { The personal information that I provide on this web site is } \\
\text { secure. }\end{array}$ & 0.816 \\
\hline & $\begin{array}{l}\text { This web site will not use unsuitable methods to collect my } \\
\text { personal data. }\end{array}$ & 0.694 \\
\hline & This web site does not ask for irrelevant personal information. & 0.858 \\
\hline & $\begin{array}{l}\text { This web site does not apply my personal information for other } \\
\text { purposes. }\end{array}$ & 0.924 \\
\hline \multirow{4}{*}{$\begin{array}{l}\text { Trust } \\
\text { Propensity } \\
(0.8618)\end{array}$} & $\begin{array}{l}\text { I tend to trust a person/thing, even though I have little } \\
\text { knowledge of it. }\end{array}$ & 0.853 \\
\hline & Trusting someone or something is not difficult. & 0.861 \\
\hline & I feel that people are generally reliable & 0.749 \\
\hline & I generally trust other people unless they give me reason not to & 0.700 \\
\hline \multirow{3}{*}{$\begin{array}{l}\text { Web } \\
\text { Experience } \\
(0.8520)\end{array}$} & I am quite comfortable using computers. & 0.849 \\
\hline & I am quite comfortable surfing the Internet. & 0.892 \\
\hline & I consider myself computer and net-savvy. & 0.805 \\
\hline \multirow{3}{*}{$\begin{array}{l}\text { Intention to } \\
\text { use } \\
(0.8210)\end{array}$} & I will use the social networking site frequently in the future. & 0.930 \\
\hline & I expect to use the social networking site in the near future. & 0.886 \\
\hline & I intend to use the social networking Website & 0.759 \\
\hline \multirow{4}{*}{$\begin{array}{l}\text { Intensity of } \\
\text { use } \\
(0.8473)\end{array}$} & The social networking site is part of my everyday activity. & 0.840 \\
\hline & The social networking site has become part of my daily routine. & 0.906 \\
\hline & $\begin{array}{l}\text { I feel out of touch when I haven't logged onto the social } \\
\text { networking site for a while. }\end{array}$ & 0.814 \\
\hline & I feel I am part of the online social networking community. & 0.823 \\
\hline
\end{tabular}

Table 1: Validated Questionnaire Items

Finally, to test what factors influence social networking use, stepwise regression was conducted to identify the key factors of interest ${ }^{2}$. 
The analyses indicated that trust propensity, security and privacy were not significant at the 0.05 level of significance. Consequently, these factors were omitted from the path analysis using structural equation modeling (SEM). SEM was used to test the influence of the rest of the factors on social networking use. Model fit was assessed in terms of four measures identified by authorities: root mean square error of approximation (RMSEA) over 0.08, standardized root mean square residual (SRMR) over 0.10 , Tucker Lewis index (TLI or NNFI) over 0.9, and the adjusted goodness of fit index (AGFI) over 0.90 (Gefen et al. 2000). The values for the measurement model exceeded the recommended target values for each of these fit statistics. The results from the test of the structural model are presented in figure 2 .

The results indicated that desire to get information, social norms, enjoyment and web experience are statistically significant in their influence on the intention to use and consequently the intensity of use. Self esteem and the desire to give information did not influence social networking use in a statistically significant way.

\section{DISCUSSION}

In summary, in this study, enjoyment gained through social networking and the desire to get information were among the major factors that influence use and intensity of usage of social networks. These represent new dimensions with respect to the usual conceptual models of social networking, and statistically, new constructs with respect to the usual analysis. These variables also make a great deal of sense, based on past survey respondents' answers to qualitative, open-ended questions, since survey respondents have consistently emphasized both the utilitarian and the fun aspects of using social networking sites (Ariyachandra and Bertaux, 2009). Thus the results are consistent with a range of behavioral models-including the rational, utility-maximizing behavior model used by economists, whereby individuals engage in behaviors from which they expect to benefit. In this instance, benefits are expected in terms of

\footnotetext{
${ }^{2}$ The decision to conduct regression analyses prior to path analysis using structural equation modeling (SEM) was also due to the fact that the initial attempts to conduct an SEM analysis using LISREL would not converge with all the items of interest.
}

intrinsic enjoyment of the activity, and/or in terms of receiving information users find useful and/or entertaining.

In addition, social norms and web experience also influenced use and intensity of use. This also makes sense in terms of behavioral models, since web experience gives individuals a skill set that makes online social networking easier to engage in, and thus less costly in terms of time and energy. Similarly, social norms that encourage use of social networking sites indicate social approval of such usage, which can both reduce any reluctance to use, and increase the perceived benefits of usage, and thus lead to increased users and intensity of usage.

Interestingly, in this study, concerns for privacy and security as well as trust variables were not significantly correlated with social network usage. This may signify a comfort level with social networking sites that has increased along with the growth and expansion of these networks, and it may also be related to the age group of the population in this study, namely, college-aged "millenials." In this vein, Facebook's chief executive Mark Zuckerberg recently declared the end of "the age of privacy" (Schneier, 2010). Given the real risks and dangers associated with disclosure of personal information on social networking sites, it may be that young people display an unwise lack of concern in this area, even when informed of the dangers, perhaps due to the high value they place on the information given and received (Knox, 2010). Others argue that while young people may put personal information on social networking sites that seems private to older people, young people still react strongly when they feel their privacy limits are overstepped (Schneier, 2010). Controversy in this area is likely to continue, as it may be that privacy, trust, and security concerns are a moving target - that is, attitudes may be evolving and changing even as studies are performed.

The other variables that were not statistically significant in this study, the desire to give information and self-esteem, may indicate that at least in the population studied here, individuals are less likely to be using online social networking from these motivational viewpoints than had been hypothesized. Again, there may be a moving target here, as the exponential growth in users of these sites may mean that a threshold in use may have been reached whereby 
use is expected by the majority, and therefore individual psychological reasons for using social networking sites are becoming of lesser proportional importance.

\section{CONCLUSION}

This paper has summarized a comprehensive conceptual model of influences on social networking usage, and has presented analysis and results from data collected in the United States. These results suggest that individuals' desire to get information and their enjoyment of social networking sites significantly influence both their decision to use such sites, and the intensity with which the sites are utilized. Web experience and social norms are also identified as significant influences on usage. Further, privacy and trust concerns appear to be eclipsed by the enjoyment and desire to get information from social networking; similarly self-esteem and the desire to give information did not appear as significant influences. This research therefore adds to our understanding of who uses social networking and why, in the population studied.

This study represents an initial phase of a proposed research project that seeks to identify the factors that influence social networking use across cultures. Currently, the main phase of the project is underway as data is being collected from various countries across the world. This will allow analysis of cultural and inter-cultural factors; based on the significance of social norms found in the current study, and the connection between culture and social norms, this is expected to yield interesting results. An additional and essential area for further study would be studies that collect data across the age spectrum, as older users of social networking sites are growing rapidly (Boyd and Ellison, 2007). Finally, to the extent that relationships among variables are changing over time, longitudinal studies that follow individuals over time would also be a welcome addition to the literature.

\section{REFERENCES}

Abu-Rashed, J., Bertaux, N., \& Okunoye, A. (2007). Information technology education for women in developing countries: Benefits, barriers, and policies. Global Business and Economic Review, 9(4), 353-365.
Acquisti, A., \& Gross, R. (2006). Imagined communities: Awareness, information sharing, and privacy on the facebook. Proccedings of the Privacy Enhancing Technologies Workshop (PET), 2006,

Anderson, P. (2007). What is web 2.0? ideas, technologies and implications for education. Technology and Standards Watch, JISC.

Ariyachandra, T., \& Bertaux, N. (2010). Factors that influence the use of social networking sites: A study of midwestern U.S. college students . Journal of Management and Engineering Integration, 2.

Associated Press. (2010). Study: Young adults do care about online privacy. NPR.Org, April 15,2010

Belanger, F., Hiller, J. S., \& Smith, W. J. (2002). Trustworthiness in electronic commerce: The role of privacy, security, and site attributes. Journal of Strategic Information Systems, 11, 245-270.

Bolton, G., Loebecke, C., \& Ockenfels, A. (2008). Does competition promote trust and trustworthiness in online trading? an experimental study. Journal of Management Information Systems, 25(2), 145-169.

Bonneau, J., \& Preibusch, S. (2009). The privacy jungle: On the market for data protection in social networks. The Eighth Workshop on the Economics of Information Security,

Boyd, D. M. (2004). Friendster and publicly articulated social networks. Proceedings of the Conference on Human Factors and Computing Systems, ACM, Vienna, 2004.,

Boyd, D., \& Ellison, N. (2007). Social network sites: Definition, history, and scholarship. Journal of Computer-Mediated Communication, 13(1)

Boyd, D. (2007). Why youth love social network sites: The role of networked publics in teenage social life. The John D.and Catherine T.MacArthur Foundation Series on Digital Media and Learning, -, 119-142.

Brown, J., Broderick, A. J., \& Lee, N. (2007). Word of mouth communication within online 
communities: Conceptualizing the online social network. Journal of Interactive Marketing (John Wiley \& Sons), 21(3), 2-20.

Cain, J. (2008). Online social networking issues within academia and pharmacy education. American Journal of Pharmaceutical Education, 72(1).

Cardon, P., Marshall, B., Norris, D. T., Cho, J., Choi, J., Cui, L., Collier, C., El-Shinnaway, M., Goreva, N., Nillson, S., North, M., Raungpaka, V., Ravid, G., Svensson, L., Usluata, A., Valenzuala, J. P., Wang, S., \& Whelan, C. (2009). Online and offline social ties of social network website users: An exploratory study in eleven societies. Journal of Computer Information Systems, 50(1), 5464.

Chapman, C. N., \& Lahav, M. (2008). International ethnographic observation of social networking sites. Conference on Human Factors in Computing Systems. , 3123-3128.

Chen, Y., \& Barnes, S. (2007). Initial trust and online buyer behavior. Industrial Management \& Data Systems, 107(1), 21-36.

Chesney, T., Foster, D., \& Lawson, S. (2010). Explaining technology adoption with information cascades, a study of microblogging data (april 23, 2010). Nottingham University Business School Research Paper no. 2010-09,

Chi, L., Wai, K. C., Seow, G., \& Tam, K. (2009). Transplanting social capital to the online world: Insights from two experimental studies. Journal of Organizational Computing \& Electronic Commerce, 19(3), 214-236. doi:10.1080/10919390903041931

Comrey, A., \& Lee, H. (1992). A first course in factor analysis. Hillsdale, NJ: Lawrence Ehrlbaum Associates.

Dangson, C. (2009). Socialising the enterprise: Breaking down operational barriers to success. IDC Presentation,

Davenport, T. H., \& Klahr, P. (1998). Managing customer support knowledge. California Management Review, 40(3), 195208.
Dwyer, C., Hiltz, S. R., \& Passerini, K. (2007). Trust and privacy concern within social networking sites: A comparison of facebook and MySpace. Proceedings of the Thirteenth Americas Conference on Information Systems, Keystone, Colorado August 2007.

Eastin, M. S., \& LaRose, R. (2000). Internet self-efficacy and the psychology of the digital divide. Journal of Computer-Mediated Communication, 6(1).

Ellison, N. B., Steinfield, C., \& Lampe, C. (2007). The benefits of facebook "friends:" social capital and college students' use of online social network sites. Journal of Computer-Mediated Communication, 12(4).

Facer, K., \& Selwyn, N. (2010). Social networking: Key messages from the research. In R. Sharpe, H. Beetham \& S. de Freitas (Eds.), Rethinking learning for a digital age: How learners are shaping their own experiences (). London: Routledge.

Flint, D. (2009). Law shaping technology: Technology shaping the law. International Review of Law, Computers \& Technology, 23(1), 5-11. doi:10.1080/13600860902742505

Fogg, B. J., \& Iizawa, D. (2008). Online persuasion in facebook and mixi: Crosscultural comparison. Lecture Notes in Computer Science, , 35-46.

Gefen, D., Straub, D.W., Boudreau, M.C. (2000). Structural equation modeling and regression: Guidelines for research practice. Communications of the Association for Information Systems, 4(7), 1-77.

Gianino, C.Many colleges using facebook to penalize students. Retrieved December 22, 2008, from http://www.mcquadrangle.com

Goby, V. P. (2006). Theory of planned behavior as the basis for internet shopping-questionnaire. CyberPsychology \& Behavior, 9(4), 423-431.

Gretzel, V., Kang, M., \& Lee, W. (2008). Differences in consumer-generated media adoption and use: A cross-national perspective. Journal of Hospitality and Leisure Marketing, 17(1 \& 2), 99-120. 
Grover, V., \& Davenport, T. H. (2001). General perspectives on knowledge management: Fostering a research agenda. Journal of Management Information Systems, $18(1), 5-21$.

Hampton, K., Sessions, L., Her, E. J., \& Rainie, L. (2009). Social isolation and new technology. Pew Internet \& American Life Project,

Hargittai, E. (2007). Whose space? differences among users and non-users of social network sites. Journal of Computer-Mediated Communication, 13(1).

Hinkin, T. R. (1995). A review of scale development practices in the study of organizations. Journal of Management, 21(5), 967-988.

Jackson, M. (2007). Exploring gender, feminism and technology from a communication perspective: An introduction and commentary. Women's Studies in Communication, 30(2), 149.

Jaffray, P. (July 2009). Pay to play: Paid internet services. Piper Jaffray Investment Research,

Jue, A., Marr, J. A., \& Kassotakis, M. E. (2009). Social media at work: How networking tools propel organizational performance. Hoboken, New Jersey: Wiley, John \& Sons, Incorporated.

Kent, J. (2008). Social networking sites: Will they survive. Nebula, 5.1/5.2, 44-50.

Kent, J. (2008). Social networking sites: Will they survive? Nebula, 5(1-2), 44-50.

Khatri, N., Tsang, E. W. K., \& Begley, T. M. (2003). Cronyism: The downside of social networking Academy of Management.

Kim, J., LaRose, R., \& Peng, W. (2009). Loneliness as the cause and the effect of problematic internet use: The relationship between internet use and psychological wellbeing. CyberPsychology \& Behavior, 12(4), 451-455. doi:10.1089/cpb.2008.0327

Kim, Y., \& Lee, W. (2009). Philanthropy via social network sites: Application of the theory

Volume XI, No. 1, 2010 of reasoned action to donation in social network sites. American Academy of Advertising Conference Proceedings, , 94-94.

Knox, R. (2010). The teen brain: It's just not grown up yet. NPR.Org, March 1, 2010

Kumar, R., Novak, J., \& Tomkins, A. (2006). Structure and evolution of online social networks. Proceedings of the 12th ACM SIGKDD International Conference on Knowledge Discovery and Data Mining, Philadelphia, PA, USA.

Lewis, C., \& George, J. (2008). Cross-cultural deception in social networking sites and faceto-face communication. Comput.Hum.Behav., 24(6), 2945-2964.

doi:10.1016/j.chb.2008.05.002

Lewis, K., Kaufman, J., Gonzalez, M., Wimmer, A., \& Christakis, N. (2008). Tastes, ties, and time: A new social network dataset using facebook.com. Social Networks, 30(4), 330-342. doi:DOI:

10.1016/j.socnet.2008.07.002

Li, C., \& Bernoff, J. (2009). Groundswell: Winning in a world transformed by social technologies. Boston, MA: Harvard Business Press.

Lull, J. (2007). Culture-on-demand: Communication in a crisis world. Oxford: Blackwell.

MacMillan, . (2009). Facebook, meet the locals. Business Week Online, , 21-21.

Marshall, B., Cardon, P., Norris, D., Goreva, N., \& D'Souza, R. (2008). Social networking websites in india and the united states. Issues in Information Systems, IX(2), 87-94.

McAfee, A. (2009). Enterprise 2.0: New collaborative tools for your organization's toughest challenges. Boston, MA: Harvard Business School Publishing.

McKnight, D. H., Choudhury, V., \& Kacmar, C. (Sept. 2005). Developing and validating trust measures for e-commerce. Information Systems Research, 13(3), 355.

Mikami, A. Y., Szwedo, D. E., Allen, J. P., Evans, M. A., \& Hare, A. L. (2010). 
Adolescent peer relationships and behavior problems predict young adults' communication on social networking websites. Developmental Psychology, 46(1), $46-56$.

Miniwatts Marketing Group.Internet world stats, 2010., May 8, 2010. Retrieved from http://www.internetworldstats.com/stats.htm

Mislove, A., Viswanath, B., Gummadi, K. P., \& Druschel, P. (2010). You are who you know: Inferring user profiles in online social networks. Proceedings of the Third ACM International Conference on Web Search and Data Mining, 251-260.

Neumann, M., O'Murchu, I., Breslin, J., \& Decker, S. (2005). Semantic social network portal for collaborative online communities. Journal of European Industrial Training, 29(6), 472.

Owyang, J. (April 2009). The future of the social web. Forrester Research.

Panzarasa, P., Opsahl, T., \& Carley, K. M. (2009). Patterns and dynamics of users' behavior and interaction: Network analysis of an online community. Journal of the American Society for Information Science \& Technology, 60(5), 911-932.

Park, C., \& Jun, J. (2003). A cross-cultural comparison of internet buying behavior: Effects of internet usage, perceived risks, and innovativeness. International Marketing Review, 20(5)

Pelling, E. L., \& White, K. M. (2009). The theory of planned behavior applied to young people's use of social networking web sites. CyberPsychology \& Behavior, 12(6), 755-759. doi:10.1089/cpb.2009.0109

Penenberg, A. (2009). Viral loop, from facebook to twitter, how today's smartest businesses grow themselves Hyperion.

Piskoriski, M. J. (Unpublished). Networks as covers: Evidence from business and social online networks.

Privacy 2.0. (2010, January 28). The Economist.
Profiting from friendship. (2010, January 28). The Economist,

Reisinger, D. (2008). 5 international social networks to keep an eye on. Retrieved January 14, 2009, from http://news.cnet.com/830117939_109-10126429-

2.html? subj=news\&tag=2547-1_3-0-

20\&part $=$ sphere

Ridingsa, C. M., Gefenb, D., \& Arinzec, B. (2002). Some antecedents and effects of trust in virtual communities. Journal of Strategic Information Systems, 11, 271-295.

Sagolla, D. (2009). 140 characters: A style guide for the short form. Hoboken, New Jersey: Wiley, John \& Sons, Inc.

Schneier, B. (2010, April 6). Google and facebook's privacy Illusion Forbes.Com.

Shih, C. (2009). The facebook era, tapping online social networks to build better products, reach new audiences, and sell more stuff. Boston, MA: Pearson Education, Inc.

Smith, J., \& Hudson, C. (2009). Inside virtual goods: The US goods market 2009-2010. Prophetic Media,

Smith, J. (2008). Intreguing trends in social networking growth during $1 \mathrm{H} 2008$. Retrieved January $\quad 14, \quad 2009, \quad$ from http://www.insidefacebook.com/2008/07/27/in triguing-trends-in-social-networking-growthduring-1h-2008/

Srite, M., \& Karahanna, E. (Sept. 2006). Role of espoused national cultural values in technology acceptance. MIS Quarterly, 30(3), 679-797.

Straub, D. W. (1989). Validating instruments in MIS research. MIS Quarterly, 13(2), 146160.

Stutzman, F. (2006). An evaluation of identitysharing behavior in social network communities. International Digital and Media Arts Journal, 3(1)

Swanson, E. B. (1994). Information systems innovation among organizations. Management Science, 40(9), 1069-1092. 
Tagvoryan, A., \& Briones, J. M. (2009). Facebook and the evolution of online privacy. Venulex Legal Summaries. , 1-2.

Taylor, S., \& Todd, P. A. (1995). Understanding information technology usage: A test of competing models. Information Systems Research, 6(2)

Tufekci, Z. (2008). Grooming, gossip, facebook and myspace. Information, Communication \& Society, 11(4), 544-564. doi:10.1080/13691180801999050 \

Venkatesh, V., Morris, M. G., Davis, G. B., \& Davis, F. D. (Sept. 2003). User acceptance of information technology: Toward a unified view. MIS Quarterly, 27(3), 425-478.

Vitartas, P., Sloan, K., Poh, P., \& Dunlop, M.An assessment of cross-cultural and social network influences on the delivery of an international teaching model ultilising a computer-mediated approach. Progress Report 2000 NextED Research Grant Recipient, , 169173.

Walsham, G. (2008). ICT's and global working in a non-flat world. Information technology in the service economy: Challenges and possibilities for the 21st century (pp. 13-25). Boston: Springer. doi:10.1007/978-0-38709768-8

Warr, W. A. (2008). Social software: Fun and games, or business tools? Journal of Information Science, 34(4), 591-604.

Wu, J., \& Liu, D. (2007). The effects of trust and enjoyment on intention to play online games.

Yammering away at the office. (2010, January 28). The Economist,

Ye, J. (2006). Traditional and online support networks in the cross-cultural adaptation of chinese international students in the united states. Journal of Computer-Mediated Communication, 11(3), 863-876.

Yi, M. Y., \& Hwang, Y. (2003). Predicting the use of web-based information systems: Selfefficacy, enjoyment, learning goal orientation, and the technology acceptance model. International Journal of Human-Computer Studies, 59, 431-449.
Youn, S. (2009). Determinants of online privacy concern and its influence on privacy protection behaviors among young adolescents. The Journal of Consumer Affairs, 43(3), 389.

Zmud, R. W., \& Boynton, A. C. (1991). Survey measures and instruments in MIS: Inventory and appraisal. In K. L. Kraemer (Ed.), The information systems research challenge: Survey research methods (pp. 75105). Cambridge, MA: Harvard Business School Press. 